\title{
Adipose-derived stem cells for treatment of chronic ulcers: current status
}

\author{
Jens Selch Holm", Navid Mohamadpour Toyserkani ${ }^{2}$ and Jens Ahm Sorensen ${ }^{1}$
}

\begin{abstract}
Chronic ulcers remain a difficult challenge in healthcare systems. While treatment options are limited, stem cells may be a novel alternative. Adipose-derived stem cells (ADSC) have become increasingly popular compared with bone marrow-derived stem cells as they are far easier to harvest. To summarize the current status of treating chronic ulcers with ADSC, this systematic review includes all clinical trials on the subject from PubMed and EmBase, as well as all registered clinical trials on ClinicalTrials.Gov. A total of nine clinical trials and fourteen registered trials were included. The studies were significantly different in terms of study design and patient population, and the overall quality of the studies was low to moderate. Despite the overall low study quality and the significant differences between the studies, some conclusions were consistent: ADSCs are safe, improve the healing of chronic ulcers, and reduce pain. As these results are consistent despite the shortcomings of the studies, they appear to highlight the efficacy of ADSCs in the treatment of chronic ulcers. Larger numbers of higher quality studies are needed to determine the precise role of ADSCs in treating chronic leg ulcers.
\end{abstract}

Keywords: Chronic ulcers, Chronic wounds, Adipose-derived stem cells, Stromal vascular fraction

\section{Background}

Chronic leg ulcers (CLU) are a common and complicated disease to treat [1], and result in high morbidity [2] and significantly reduced quality of life [3]. Normal wound healing consists of four overlapping phases: hemostasis, inflammation, proliferation, and remodeling [4]. Most ulcers heal when the cause is eliminated and the ulcer is treated with standard wound care. Some ulcers, however, are for various reasons locked in the inflammatory stage and do not heal [5]. Regarding CLUs, most of the ulcers are caused by venous insufficiency or arterial ischemia, often secondary to diabetes, but some CLUs do not have an apparent underlying condition [6].

CLUs are a challenge for the physician, a significant physical and psychological setback for the patient, and a heavy burden on the healthcare systems. Thus, an American study reported an average cost of treating chronic venous leg ulcers of $\$ 9685$ per patient per year [7]. This reflects that these patients are difficult to treat, as the available treatment options are limited, leaving

\footnotetext{
* Correspondence: jensholm87@gmail.com

${ }^{1}$ Department of Plastic Surgery, Odense University Hospital, Odense, Denmark

Full list of author information is available at the end of the article
}

patients with a chronic condition severely affecting their quality of life. CLUs result in substantial use of the resources of healthcare systems regarding materials, hospital appointments, reduced working capability for the patients, and impairment of the patient in general [8].

Treatment with stem cells might be a new treatment option for these patients. Stem cells [9] have the potential to differentiate into numerous types of cells [10]. Over the last decade, stem cell therapy has shown great potential in the treatment of a variety of different conditions, such as orthopedic disorders, inflammatory diseases, hepatic failure, and autoimmune disorders [11, 12]. At the time of writing, adverse events have not been reported; therefore, stem cell treatment is currently regarded as safe [13]. A review [14] including more than 1400 patients found a favorable safety profile of adipose-derived stem cells (ADSC), but also highlighted the poor quality of most studies in regard to registering adverse events.

Adipose tissue is an excellent source of autologous ADSC and can be harvested easily compared with bone marrowderived stem cells (BMSC) [15]. Adipose tissue has in recent years surpassed bone marrow as the preferred source of mesenchymal stem cells [16]. Besides being abundant, far easier to harvest, and with a lower risk of complications 
for the patient, adipose tissue additionally contains about 40 times more stem cells than bone marrow [17]. A simple liposuction of the abdomen or inner thigh performed under local or general anesthesia is sufficient to harvest the required number of ADSC without any significant risk of complications [18]. ADSC can be either freshly isolated or cultured. The culturing takes several days or weeks, and cannot be performed as a same-day procedure.

Stem cells are a heterogeneous pool of cells with numerous capabilities [19]. They possess anti-inflammatory and neoangiogenic effects, secrete numerous growth factors, and can differentiate into various cells types [20]. Many of these are known to be involved in the complex healing of wounds [21], although the exact capabilities and mechanisms of action of stem cells in wound healing are not yet fully understood. Research suggests that stem cells work though two mechanisms of action: firstly they attenuate the general inflammatory response and, secondly, they transform into cells involved in wound healing such as fibroblasts, myofibroblasts, antigen presenting cells, endothelial progenitor cells, and so forth [22].

Freshly isolated ADSC are far more heterogeneous compared with the quite homogeneous cells harvested from cultured ADSC [23]. The greater variety of cell types in the freshly isolated ADSC could have a significant advantage in wound healing, compared with the far more limited number of different cells in cultured ADSC. In ADSC, endothelial, hematopoietic, and pericytic lineages represent $10-20 \%, 25-45 \%$, and $3-5 \%$, respectively, of the total nucleated cells.

Several methods of isolating ADSC have been reported $[16,24]$. The most common is enzymatic isolation. Some techniques use simple centrifugation and vibration to isolate a stem cell pellet. Others are more complex and involve, for example, enzymatic (collagenase) dissolving of the adipose tissue. Fully automatic systems also exist. The different methods have advantages and disadvantages regarding the time required for the procedure, the need for advanced equipment/specially trained personnel, and financial cost. Data describing the efficacy of various methods are not available; therefore, no standardized method exists [25]. In addition, the optimal method of application of ADSC is still undecided.

Various animal studies have documented the positive effect of ADSC in accelerating healing of chronic ulcers [19]. The clinical translation is ongoing, with several clinical studies already published. The aim of this review is to describe the available data on the treatment of CLU with autologous ADSC by identifying published human studies and ongoing/registered clinical trials on the matter.

\section{Data acquisition}

To identify the relevant clinical trials, a search was performed on PubMed and EmBase for all human studies in
English on ADSC in the treatment of chronic ulcers (Fig. 1) according to the PRISMA statement [26]. The search was performed in December 2017 independently by both the first and second author of this article by using the search terms: ("adipose-derived stem cells" OR "adipose stem cells" OR "stromal vascular fraction" OR "mesenchymal cells" OR "stromal cells") AND ("wound healing” OR "ulcer"). Articles from 1 January 1995 to December 2017 were included. A similar search was performed on EmBase.

In total, 3404 articles were identified after duplicates were removed $(n=956)$ using Covidence [27]. The titles and abstracts were screened, and 3352 articles not relevant to the subject were excluded, leaving 52 articles that were potentially relevant and the full articles were obtained for further review. Of these, 43 studies were excluded (see Fig. 1 for more detail) and a total of nine clinical studies were identified and included in the review (Table 1). Their reference lists were evaluated manually for additional studies. Author/year, title, cause of ulcer, patient population, study design, type of ADSC, application method, primary endpoints, follow-up duration, and conclusions were recorded from the included studies. For a full overview of the results, see Table 1 .

To identify past, ongoing, or future registered studies on ADSC in the treatment of chronic ulcers, a thorough search of ClinicalTrials.gov was performed. Using the search terms "stem cells" or "adipose" or "stromal cells" in combination with "ulcer" or "wound", a total of fourteen studies were identified (Table 2).

Study title, type of ADSC and application method, study design, cause of ulcer, trial institution, NCT number, duration period, and study status were recorded.

\section{Results}

\section{Published clinical studies}

The clinical trials included in the review were: study 1 , Han et al. [28]; study 2, Kirana et al. [29]; study 3, Marino et al. [30]; study 4, Bura et al. [31]; study 5, Raposio et al. [32]; study 6, Carstens et al. [33]; study 7, Chopinaud et al. [34]; study 8, Konstantinow et al. [35]; and study 9, Darinskas et al. [36].

The data were collected as described in the Data acquisition section; for the full overview of the included studies and data, refer to Table 1.

\section{Cause of chronic ulcers}

All studies except study 3 included patients with peripheral artery disease (PAD). PAD was primarily a complication to diabetes (studies 1, 2, 6, 7, 8, and 9), thromboangiitis obliterans (study 5) or primary atherosclerosis (study 4). Studies 3 and 4 included patients with hypertensive and venous ulcers. Study 3 had only hypertensive/venous ulcers, whereas study 4 had $45 \%$ hypertensive/venous ulcers. Study 8 included 16 patients 


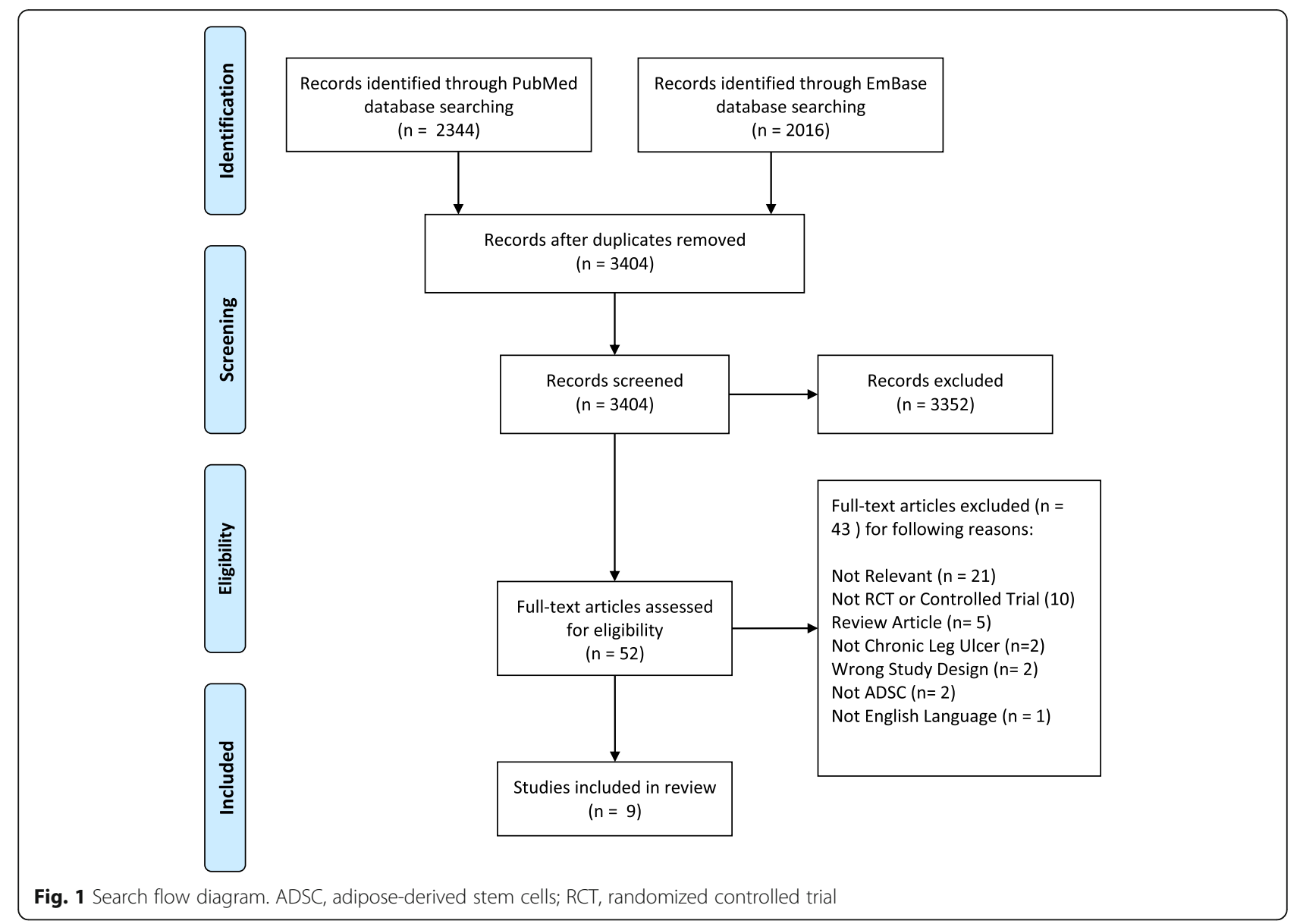

of which nine had arterial-venous disease and seven patients with venous disease.

\section{Study design}

The studies varied significantly in study design. No studies were blinded and only studies 1 and 5 were randomized. Three studies (1, 3, and 5) had control groups. The size of the groups ranged from 7 to 28 patients in the case groups and from 0 to 28 patients in the control groups, and the total number of patients included ranged from 7 to 54 patients. The follow-up period varied from 2 months (study 1) to 18 months (studies 5 and 6).

\section{Type of ADSC}

Different types of stem cells were used in the studies. Freshly isolated stem cells were used in studies $1,3,5,6$, 7,8 , and 9 , and cultured cells were used in studies 2 and 4. All studies used adipose tissue harvested from the abdomen or inner thigh using liposuction.

Studies 1 and 6 isolated an ADSC pellet using collagenase and centrifugation. Studies 2 and 4 used cultured stem cells digested with collagenase and centrifuged. In study 3 , a Celution $800^{\circ}$ system isolated the ADSC. In study 5, e-PRP (platelet-rich plasma combined with
ADSC isolated using vibration and centrifugation) was the type of ADSC investigated. Study 7 isolated the ADSC with the LipoStructure [37] technique. Study 8 isolated the ADSC with the Transpose $\mathrm{RT}^{\mathrm{Tm}}$ Processing Unit (TPU; InGeneron Inc., Houston, TX, USA).

Study 9 investigated uncultured ADSC isolated without collagenase using mechanical isolation (the fat was minced using a metal mill and subsequently centrifuged).

\section{Application method}

The application method varied from study to study. Topical application of the stem cells onto the wound was performed in study 1 . Studies 2, 4, 6, and 9 injected the ADSC intramuscularly. In study 3 , the stem cells were injected around the ulcer and, in studies 5 and 7 , the stem cells were injected into and around the ulcer. Study 8 injected the ADSC into and around the ulcer, but also applied $2.5 \mathrm{~mL}$ of ADSC onto a sponge which was fixed on top of the ulcer.

\section{Ulcer healing}

All studies reported healing of the chronic ulcers to varying degrees. The results reported were: 


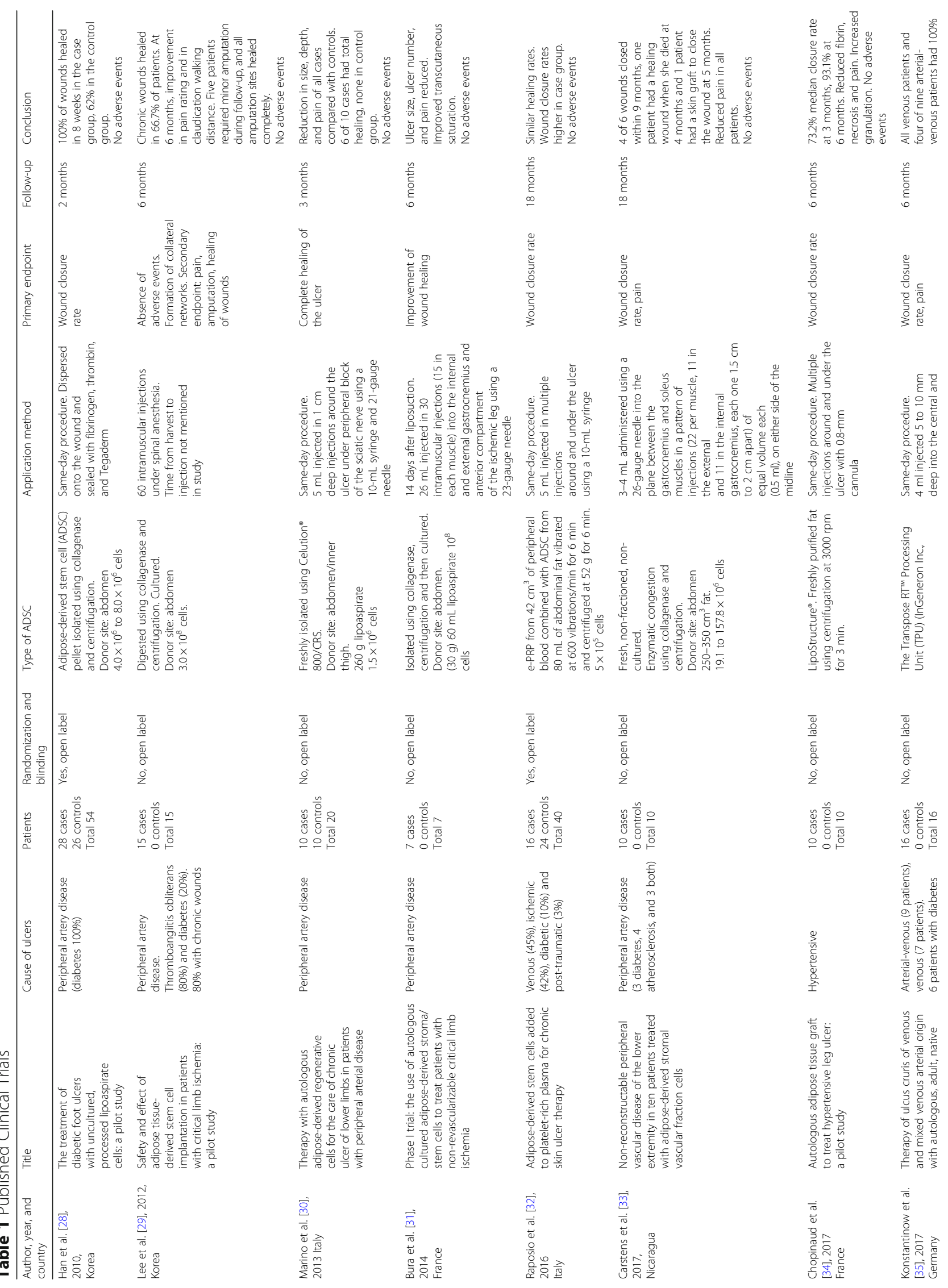









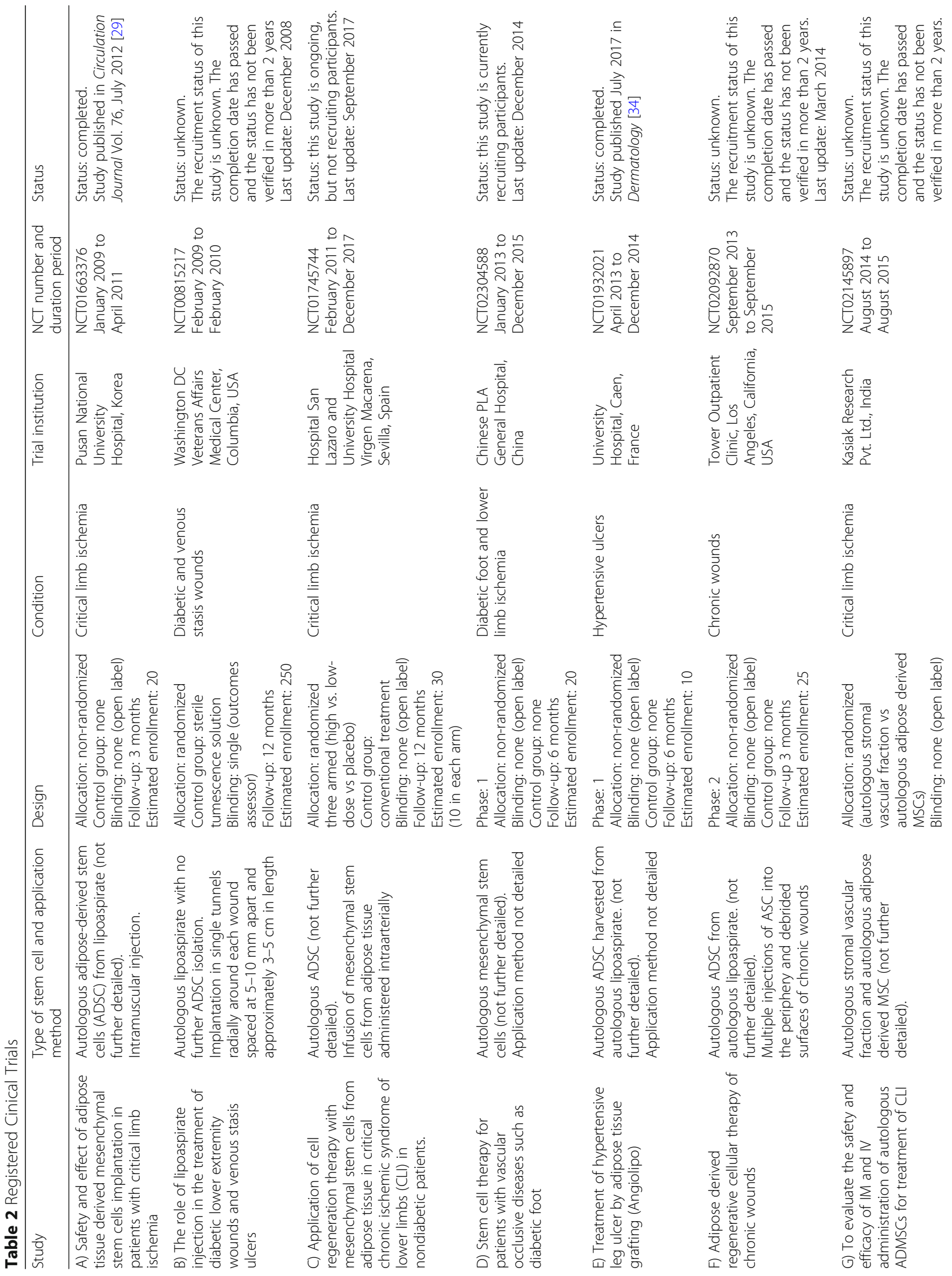




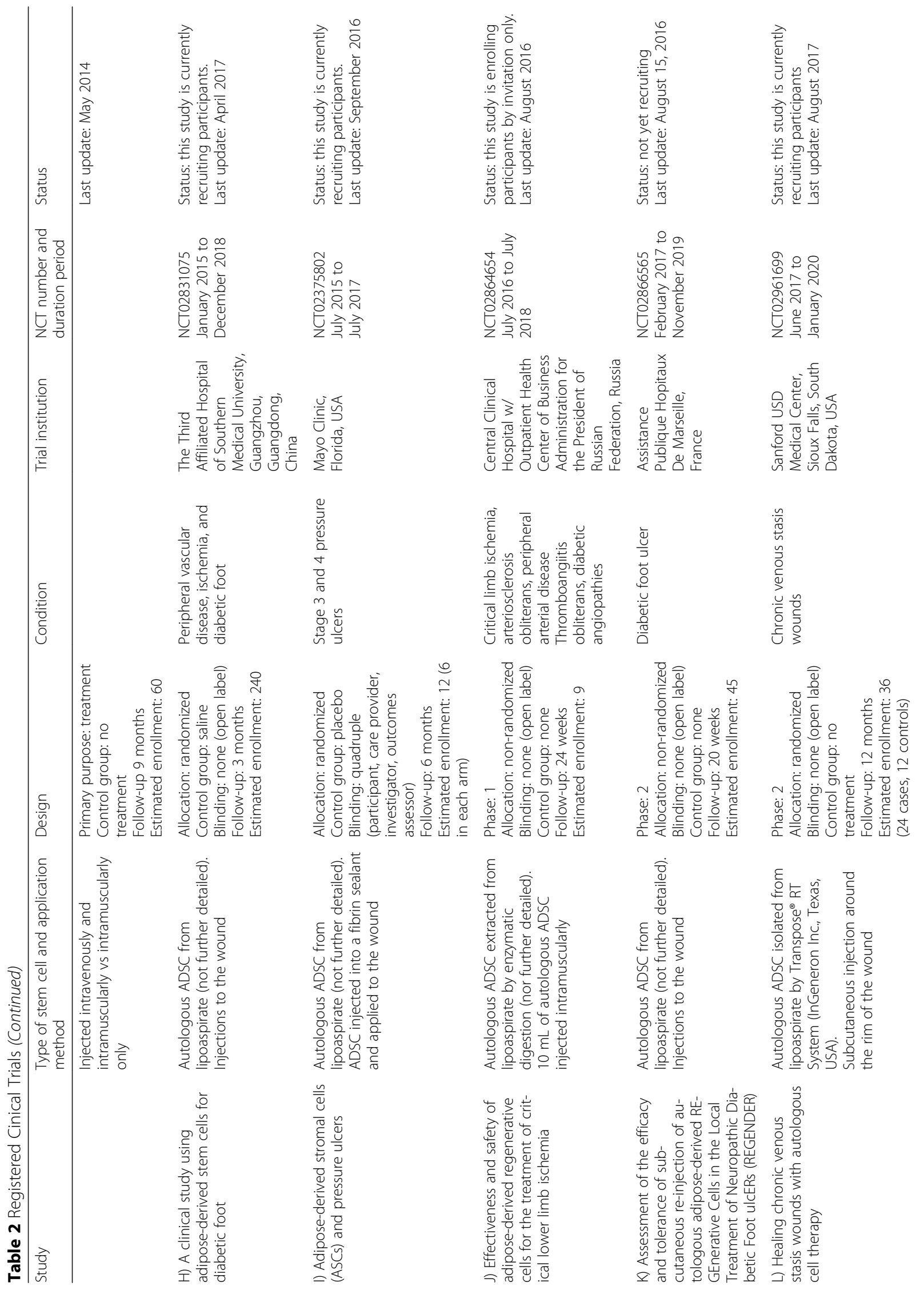




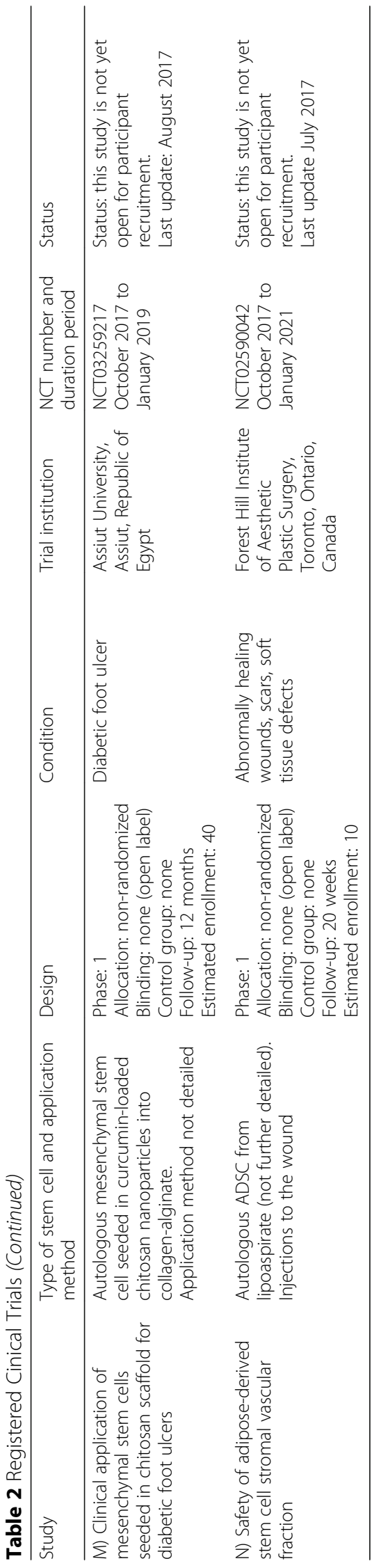


- Study 1: 100\% healing of the case group compared with $62 \%$ in the control group.

- Study 2: $66.7 \%$ of the chronic ulcers had healed at 6 months.

- Study 3: Six out of ten patients in the case group had total healing of the ulcer versus none in the control group.

- Study 4: A decrease in the number of ulcers and in ulcer size in all patients, except two patients where amputation was performed.

- Study 5: Reported similar total ulcer healing rates between the case and the control group (71\% vs $68 \%)$, but a significantly higher wound closing rate in the case group $\left(0.2287 \mathrm{~cm}^{2} /\right.$ day vs $0.0890 \mathrm{~cm}^{2} /$ day, $p=0.0257)$.

- Study 6: Four of six wounds closed within 9 months. Regarding the remaining two patients, one patient had a wound in the granulation stage when she died of unrelated cardiac arrest at 4 months and the other patient had a successful skin graft to close the wound at 5 months, where the ulcer was in the granulation stage.

- Study 7: A 73.2\% median closure rate at 3 months and $93.1 \%$ at 6 months.

- Study 8: All venous ulcers and four of nine arterialvenous ulcers healed. Complete wound closure was achieved within 9 to 26 weeks of ADSC treatment.

- Study 9: Seven patients with ulcers. All ulcers healed, although two patients required major amputation after which the amputation sites healed.

\section{Study conclusions}

The overall quality of the studies is low to moderate. The patient populations are limited in size and only a few studies are randomized. The lack of blinding in all studies as well as the limited randomization significantly increases the risk of bias. Quadruple blinding, larger study populations, matched control groups, and more homogenous studies would significantly improve the current research. Basic research investigating optimal dosage of stem cells and the administration route is also lacking.

Despite the shortcomings in terms of quality of the studies, and the studies being heterogeneous, some conclusions are consistent:

1) No studies report any adverse event of significance, if any at all.

2) In all studies examining wound-related pain, they all found a reduction in the sensation of pain following stem cell treatment (studies 2, 3, 4, 6, 7, 8, and 9).

3) All studies showed noteworthy progress in the healing of the chronic ulcers. In the studies with control groups, a significantly higher healing rate of the case groups compared with the control groups was seen.

\section{Registered clinical trials}

All relevant clinical trials registered on www.ClinicalTrials.gov were included (in total fourteen studies; see Table 2 for full overview of the studies).

\section{Status}

A few studies were completed, and the results published (studies $A$ and $E$ ), while most were either ongoing $(C, H$, $\mathrm{I}$, J, and $\mathrm{L}$ ), not yet recruiting patients $(\mathrm{K}, \mathrm{M}$, and $\mathrm{N}$ ) or have exceeded the anticipated completion date considerably without an update for years (B, D, F, and G).

\section{Study design}

The study design varies from study to study. Studies B, C, G, H, I, and L are randomized, but only study I and B are blinded. Studies B, C, H, I, and L have control groups. Estimated enrollment of patients ranges from 9 (J) to 250 (B). The follow-up period ranges from 3 months (A, F, and $\mathrm{H})$ to 12 months (B, C, L, and $\mathrm{M})$.

\section{Cause of chronic ulcers}

Several causes of ulcers are included in the studies. Critical limp ischemia (A, C, G, and J), diabetic foot ulcers $(\mathrm{D}, \mathrm{K}$, and $\mathrm{M})$, pressure ulcer (I), chronic venous stasis ulcers (L), and hypertensive ulcers (E) were the diagnoses involving a single underlying condition. Study $B$ includes both diabetic and venous ulcers and studies $\mathrm{D}$ and $\mathrm{H}$ include diabetic foot ulcers and lower limp ischemia. Study J examines critical limp ischemia, thromboangiitis obliterans, and diabetic foot ulcers. Study F includes chronic wounds without further specification.

\section{Type of ADSC}

Most studies utilize autologous ADSC from lipoaspirate without further specification (studies A, C, D, E, F, G, H, I, K, M, and N). However, study B uses autologous lipoaspirate with no further ADSC isolation, study J uses ADSC extracted by enzymatic digestion, study L isolates the ADSCs using the Transpose ${ }^{\bullet}$ RT System, and study $\mathrm{M}$ involves stem cells seeded in curcumin-loaded chitosan nanoparticles into collagen-alginate.

\section{Application method}

Intramuscular injection is planned for studies A and J. Injection into or around the wound is planned in studies B, F, H, K, L, and N. Study C involves intra-arterial administration of the stem cells. In study I, the ADSC are injected into a fibrin sealant and applied to the wound. Studies D, $\mathrm{E}$, and $\mathrm{M}$ do not explain how the stem cells are planned to be applied. Study G applies intravenous and intramuscular injection versus intramuscular injection only. 


\section{Summary}

As in the published clinical studies in this field, the registered clinical studies differ significantly. No consistency was observed across isolation technique, application method, or dose of ADSC. Furthermore, several different causes of ulcer are being investigated and the study designs are different. A few of the studies have been published, some are ongoing, but some of the studies have surpassed their estimated completion date and the status is unknown. Whether these studies will ever be completed/published remains questionable. Not all ongoing clinical trials are necessarily registered on ClinicalTrials.gov, however, and there is no doubt that a considerable amount of research in this field is currently being conducted, and probably even more clinical trials than the registered trials are currently being conducted.

\section{Discussion}

This systematic review concludes that current clinical studies report that ADSC are safe, improve the healing of chronic ulcers, and reduce pain. Interestingly, these findings are consistent despite the overall poor study quality, with a risk of significant bias and major diversity between the studies regarding study design, underlying conditions, methods of isolation, and methods of application. This finding might show that ADSC have a significant effect on chronic wounds of many etiologies and are not particularly dependent on isolation and administration techniques. On the other hand, one could argue that the effect seen is caused by the substantial risk of bias and not by the effect of the stem cells.

The published studies, as well as the ongoing studies, on the subject are all diverse in study design. This is because several key questions remain unanswered in the field of autologous ADSC in the treatment of chronic ulcers: What method of isolating ADSC is superior? What conditions can be treated? Which application method is best? What amount of stem cells is needed? To answer these questions, large blinded and randomized studies as well as additional basic research on the biology and capabilities of stem cells are needed. High-quality blinded, randomized studies in this field are still lacking, although a few appear to be ongoing. A significant amount of research in this field appears to be ongoing. Further studies, however, are needed to define the long-term safety and efficacy of ADSC.

In summary, BMSC and ADSC appear to have a positive effect on the healing of chronic wounds [38]. A systematic review and meta-analysis of BMSC in treatment of chronic leg ulcers [39] found that BMSC, like ADSC, are both safe and efficient. BMSC and ADSC seem to be alike in terms of differentiation capacities and immunemodulatory properties [40]. If this is true, ADSC would inarguably be the preferred type of stem cell due to the less invasive harvesting procedure needed to obtain them and the abundance of fat for harvesting compared with bone marrow. BMSC thus have no apparent advantages over ADSC. Automatic closed systems have now enabled ADSC treatment to be a fast and safe same-day procedure, making the treatment favorable but also costly. The high financial cost of standard chronic wound care means that, although stem cell treatment is expensive, it might be cheaper in the long-term and can potentially save society a substantial amount of resources if able to heal the chronic wound compared with life-long wound care. Some low-quality studies [41] report an effect of simply transplanting fat without isolation of the stem cells, which could be an alternative treatment option if resources are limited.

A limit to this study is the diversity of the studies included. The number of clinical trials in this field is still limited. Definitive conclusions on the matter are not possible, as large studies with high quality and low risk of bias are needed.

\section{Conclusion}

In conclusion, ADSC appear to be safe and have a positive effect on the healing of chronic ulcers. Treatment options for chronic ulcers are currently extremely limited and few new treatments are under development. Treatment with ADSC, however, is a novel and very exciting new treatment for chronic ulcers and might soon earn a pivotal role in this treatment; future studies will define exactly what that role will be.

\section{Availability of data and materials}

Data sharing is not applicable to this article as no datasets were generated or analyzed during the current study.

\section{Authors' contributions}

The study was performed from an idea of JAS. JSH and NMT performed the systematic literature review and JSH drafted the manuscript, which was edited by NMT and JAS. All authors read and approved the final manuscript.

Ethics approval and consent to participate

Not applicable.

\section{Competing interests}

The authors declare that they have no competing interests.

\section{Publisher's Note}

Springer Nature remains neutral with regard to jurisdictional claims in published maps and institutional affiliations.

\section{Author details}

${ }^{1}$ Department of Plastic Surgery, Odense University Hospital, Odense, Denmark. ' Department of Plastic Surgery, Roskilde Hospital, Roskilde, Denmark.

Published online: 15 May 2018

References

1. Cherubino M, Rubin JP, Miljkovic N, Kelmendi-Doko A, Marra KG. Adiposederived stem cells for wound healing applications. Ann Plast Surg. 2011; 66(2):210-5. https://doi.org/10.1097/SAP.0b013e3181e6d06c. 
2. Escandon J, Vivas AC, Tang J, Rowland KJ, Kirsner RS. High mortality in patients with chronic wounds. Wound Repair Regen. 2011;19(4):526-8. https://doi.org/10.1111/j.1524-475X.2011.00699.x.

3. Renner R, Gebhardt C, Simon JC, Seikowski K. Changes in quality of life for patients with chronic venous insufficiency, present or healed leg ulcers. J Dtsch Dermatol Ges. 2009;7(11):953-61. https://doi.org/10.1111/j.1610-0387. 2009.07082.x.

4. Guo S, Dipietro LA. Factors affecting wound healing. J Dent Res. 2010;89(3): 219-29. https://doi.org/10.1177/0022034509359125.

5. Menke NB, Ward KR, Witten TM, Bonchev DG, Diegelmann RF. Impaired wound healing. Clin Dermatol. 2007;25(1):19-25. https://doi.org/10.1016/j. clindermatol.2006.12.005

6. Agale S. Chronic leg ulcers: epidemiology, aetiopathogenesis, and management. Ulcers. 2013;2013 https://doi.org/10.1155/2013/413604.

7. Olin JW, Beusterien KM, Childs MB, Seavey C, McHugh L, Griffiths RI. Medical costs of treating venous stasis ulcers: evidence from a retrospective cohort study. Vasc Med. 1999;4(1):1-7. https://doi.org/10.1177/1358836X9900400101.

8. Psychosocial aspects in patients with chronic leg ulcers. WOUNDS. 2017. http://www.woundsresearch.com/article/psychosocial-aspects-patientschronic-leg-ulcers. Accessed 29 Jan 2018.

9. Dominici M, Le Blanc K, Mueller I, et al. Minimal criteria for defining multipotent mesenchymal stromal cells. The International Society for Cellular Therapy position statement. Cytotherapy. 2006;8(4):315-7. https:// doi.org/10.1080/14653240600855905.

10. Zuk PA, Zhu M, Ashiian P, et al. Human adipose tissue is a source of multipotent stem cells. Mol Biol Cell. 2002;13(12):4279-95. https://doi.org/10. 1091/mbc.E02-02-0105

11. Tabatabaei Qomi R, Sheykhhasan M. Adipose-derived stromal cell in regenerative medicine: a review. World J Stem Cells. 2017;9(8):107-17. https://doi.org/10.4252/wjsc.v9.i8.107.

12. Mizuno $\mathrm{H}$. Adipose-derived stem cells for tissue repair and regeneration: ten years of research and a literature review. J Nippon Med Sch. 2009;76(2):56-66.

13. Zollino I, Zuolo M, Gianesini S, et al. Autologous adipose-derived stem cells: basic science, technique, and rationale for application in ulcer and wound healing. Phlebology. 2017;32(3):160-71. https://doi.org/10.1177/0268355516 641546.

14. Toyserkani NM, Jørgensen MG, Tabatabaeifar S, Jensen CH, Sheikh SP, Sørensen JA. Concise review: a safety assessment of adipose-derived cell therapy in clinical trials: a systematic review of reported adverse events. Stem Cells Trans| Med. 2017;6(9):1786-94. https://doi.org/10.1002/sctm.17-0031

15. Kern S, Eichler H, Stoeve J, Klüter H, Bieback K. Comparative analysis of mesenchymal stem cells from bone marrow, umbilical cord blood, or adipose tissue. Stem Cells. 2006;24(5):1294-301. https://doi.org/10.1634/ stemcells.2005-0342.

16. Bertozzi N, Simonacci F, Grieco MP, Grignaffini E, Raposio E. The biological and clinical basis for the use of adipose-derived stem cells in the field of wound healing. Ann Med Surg. 2017;20:41-8. https://doi.org/10.1016/j.amsu. 2017.06.058.

17. Hassan WU, Greiser U, Wang W. Role of adipose-derived stem cells in wound healing. Wound Repair Regen. 2014;22(3):313-25. https://doi.org/10. 1111/wrr.12173.

18. Tierney EP, Kouba DJ, Hanke CW. Safety of tumescent and laser-assisted liposuction: review of the literature. J Drugs Dermatol. 2011;10(12):1363-9.

19. Toyserkani NM, Christensen ML, Sheikh SP, Sørensen JA. Adipose-derived stem cells: new treatment for wound healing? Ann Plast Surg. 2015;75(1): 117-23. https://doi.org/10.1097/SAP.0000000000000083.

20. Lauritano D, Palmieri A, Vinci R, Azzi L, Taglabue A, Carinci F. Adipose derived stem cells: basic science fundaments and clinical application. An update. Minerva Stomatol. 2014;63(7-8):273-81.

21. Demidova-Rice TN, Hamblin MR, Herman IM. Acute and impaired wound healing: pathophysiology and current methods for drug delivery, part 1: normal and chronic wounds: biology, causes, and approaches to care. Adv Skin Wound Care. 2012;25(7):304-14. https://doi.org/10.1097/01.ASW. 0000416006.55218.d0.

22. Sharma RK, John JR. Role of stem cells in the management of chronic wounds. Indian J Plast Surg. 2012;45(2):237-43. https://doi.org/10.4103/09700358.101286.

23. Bourin P, Bunnell BA, Casteilla L, et al. Stromal cells from the adipose tissuederived stromal vascular fraction and culture expanded adipose tissuederived stromal/stem cells: a joint statement of the International Federation for Adipose Therapeutics and Science (IFATS) and the International Society for Cellular Therapy (ISCT). Cytotherapy. 2013;15(6):641-8. https://doi.org/10. 1016/j.jcyt.2013.02.006.

24. Riis S, Zachar V, Boucher S, Vemuri MC, Pennisi CP, Fink T. Critical steps in the isolation and expansion of adipose-derived stem cells for translational therapy. Expert Rev Mol Med. 2015;17:e11. https://doi.org/10.1017/erm.2015.10.

25. Raposio E, Bertozzi N. Isolation of ready-to-use adipose-derived stem cell (ASC) pellet for clinical applications and a comparative overview of alternate methods for ASC isolation. Curr Protoc Stem Cell Biol. 2017;41:1F.17.1-1F.17. 12. https://doi.org/10.1002/cpsc.29.

26. PRISMA. http://prisma-statement.org/Default.aspx. Accessed 2 Jan 2018.

27. Covidence. https://www.covidence.org. Accessed 1 Dec 2017.

28. Han S-K, Kim H-R, Kim W-K. The treatment of diabetic foot ulcers with uncultured, processed lipoaspirate cells: a pilot study. Wound Repair Regen. 2010;18(4):342-8. https://doi.org/10.1111/j.1524-475X.2010.00593.X.

29. Lee HC, An SG, Lee HW, Park JS, Cha KS, Hong TJ et al. Safety and effect of adipose tissue-derived stem cell implantation in patients with critical limb ischemia: a pilot study. Circ J. 2012;76(7):1750-60. Epub 2012 Apr 12.

30. Marino G, Moraci M, Armenia E, et al. Therapy with autologous adiposederived regenerative cells for the care of chronic ulcer of lower limbs in patients with peripheral arterial disease. J Surg Res. 2013;185(1):36-44. https://doi.org/10.1016/j.jss.2013.05.024.

31. Bura A, Planat-Benard V, Bourin P, et al. Phase I trial: the use of autologous cultured adipose-derived stroma/stem cells to treat patients with nonrevascularizable critical limb ischemia. Cytotherapy. 2014;16(2):245-57. https://doi.org/10.1016/j.jcyt.2013.11.011.

32. Raposio E, Bertozzi N, Bonomini S, et al. Adipose-derived stem cells added to platelet-rich plasma for chronic skin ulcer therapy. Wounds. 2016;28(4): 126-31.

33. Carstens MH, Gómez A, Cortés R, et al. Non-reconstructable peripheral vascular disease of the lower extremity in ten patients treated with adiposederived stromal vascular fraction cells. Stem Cell Res. 2017;18:14-21. https:// doi.org/10.1016/j.scr.2016.12.001.

34. Chopinaud M, Labbé $D$, Creveuil C, et al. Autologous adipose tissue graft to treat hypertensive leg ulcer: a pilot study. Dermatolology. 2017; https://doi. org/10.1159/000478009.

35. Konstantinow A, Arnold A, Djabali K, et al. Therapy of ulcus cruris of venous and mixed venous arterial origin with autologous, adult, native progenitor cells from subcutaneous adipose tissue: a prospective clinical pilot study. J Eur Acad Dermatol Venereol. 2017; https://doi.org/10.1111/jdv.14489.

36. Darinskas A, Paskevicius $M$, Apanavicius $G$, et al. Stromal vascular fraction cells for the treatment of critical limb ischemia: a pilot study. J Transl Med. 2017;15(1):143. https://doi.org/10.1186/s12967-017-1243-3.

37. Coleman SR, Katzel EB. Fat grafting for facial filling and regeneration. Clin Plast Surg. 2015;42(3):289-300, vii. https://doi.org/10.1016/j.cps.2015.04.001.

38. Amato B, Compagna R, Amato $M$, et al. The role of adult tissue-derived stem cells in chronic leg ulcers: a systematic review focused on tissue regeneration medicine. Int Wound J. 2016;13(6):1289-98. https://doi.org/10. 1111/iwj.12499.

39. Jiang $X$, Zhang $H$, Teng $M$. Effectiveness of autologous stem cell therapy for the treatment of lower extremity ulcers: a systematic review and metaanalysis. Medicine (Baltimore). 2016;95(11):e2716. https://doi.org/10.1097/ MD.0000000000002716.

40. Hass R, Kasper C, Böhm S, Jacobs R. Different populations and sources of human mesenchymal stem cells (MSC): a comparison of adult and neonatal tissue-derived MSC. Cell Commun Signal. 2011;9:12. https://doi.org/10.1186/ 1478-811X-9-12.

41. Mohan A, Singh S. Use of fat transfer to treat a chronic, non-healing, postradiation ulcer: a case study. J Wound Care. 2017;26(5):272-3. https://doi. org/10.12968/jowc.2017.26.5.272. 